\title{
Product Characterization and Kinetics of Biomass Pyrolysis in a Three-Zone Free-Fall Reactor
}

\author{
Natthaya Punsuwan and Chaiyot Tangsathitkulchai \\ School of Chemical Engineering, Institute of Engineering, Suranaree University of Technology, Nakhon Ratchasima 30000, Thailand \\ Correspondence should be addressed to Chaiyot Tangsathitkulchai; chaiyot@sut.ac.th
}

Received 19 September 2013; Revised 24 November 2013; Accepted 28 November 2013; Published 4 February 2014

Academic Editor: Deepak Kunzru

Copyright (C) 2014 N. Punsuwan and C. Tangsathitkulchai. This is an open access article distributed under the Creative Commons Attribution License, which permits unrestricted use, distribution, and reproduction in any medium, provided the original work is properly cited.

\begin{abstract}
Pyrolysis of biomass including palm shell, palm kernel, and cassava pulp residue was studied in a laboratory free-fall reactor with three separated hot zones. The effects of pyrolysis temperature $\left(250-1050^{\circ} \mathrm{C}\right)$ and particle size $(0.18-1.55 \mathrm{~mm})$ on the distribution and properties of pyrolysis products were investigated. A higher pyrolysis temperature and smaller particle size increased the gas yield but decreased the char yield. Cassava pulp residue gave more volatiles and less char than those of palm kernel and palm shell. The derived solid product (char) gave a high calorific value of $29.87 \mathrm{MJ} / \mathrm{kg}$ and a reasonably high BET surface area of $200 \mathrm{~m}^{2} / \mathrm{g}$. The biooil from palm shell is less attractive to use as a direct fuel, due to its high water contents, low calorific value, and high acidity. On gas composition, carbon monoxide was the dominant component in the gas product. A pyrolysis model for biomass pyrolysis in the free-fall reactor was developed, based on solving the proposed two-parallel reactions kinetic model and equations of particle motion, which gave excellent prediction of char yields for all biomass precursors under all pyrolysis conditions studied.
\end{abstract}

\section{Introduction}

Pyrolysis is a viable thermal process for efficient and economical conversion of biomass into alternative energy in forms of solid char, liquid biooil, and combustible gases [1]. Based on the pyrolysis time and heating rate, the pyrolysis process can be classified into conventional and fast or flash pyrolysis. Conventional pyrolysis may also be termed "slow pyrolysis." This type of pyrolysis is defined as the one which occurs under a slow heating rate (less than $10^{\circ} \mathrm{C} / \mathrm{s}$ ), slow heat transfer rate in the reaction zone, and relatively long mean residence time [2]. Normally, conventional pyrolysis has been used mainly for charcoal production. Conversely, fast or flash pyrolysis is a thermal decomposition process that occurs at a high heating rate and short mean residence time. Heating rate of flash pyrolysis is around $100^{\circ} \mathrm{C} / \mathrm{s}$, or even $10,000^{\circ} \mathrm{C} / \mathrm{s}$, and the mean residence time is normally less than 2 seconds [2]. Flash pyrolysis process generally produces $45-75 \mathrm{wt} \%$ of liquid, $15-$ $25 \mathrm{wt} \%$ of solid, and $10-20 \mathrm{wt} \%$ of noncondensable gases, depending on the feedstock used and pyrolysis conditions.

Generally, solid, liquid, and gas produced from pyrolysis are of prime interest for use as a primary fuel. However, a number of researchers $[3,4]$ have directed attention towards investigating the effect of pyrolysis conditions on maximizing the yield of pyrolytic liquids which show promise as a substitute for petroleum based fuel. Since the liquid product or biooil from the pyrolysis process is composed of a large number of oxygenated compounds, its fuel properties do not conform to the standards of petroleum based fuels. It is therefore necessary to upgrade the crude oil along with some kinds of pretreatment before it can be fully utilized in any combustion systems [5]. Due to the numerous utility of pyrolysis products and in particular the potential application of biooil, the present work is thus concentrated on the flash pyrolysis of biomass which is capable of producing a high proportion of liquid product.

In this work, a laboratory free-fall reactor with a central heated zone is proposed for the study of biomass flash pyrolysis. A free-fall reactor has been widely used in laboratory studies on flash pyrolysis due to the following advantages: it provides high heating rate, determinations of mass balance and mean residence time are simple and straightforward [6], the mean residence time can be moderately controlled [6], and the kinetic parameters can be conveniently examined from the pyrolysis results. 
Due to a large number of complex reactions involved in the pyrolysis process, different model approaches have been proposed for the analysis of pyrolysis kinetics and mechanism such as the global kinetics model [7], the Brodi-Shafizadeh model [8], the two-parallel reactions model [9], and the three pseudocomponents model [10]. In this study, the two-parallel reactions model was adopted and used to describe the pyrolysis mechanism. According to Luangkiattikhun et al. (2008) [9], the prediction of pyrolysis kinetics by the two-parallel reactions model gave excellent fitting with the experimental results from TGA for all palm solid wastes under the pyrolysis conditions investigated. However, as opposed to studying pyrolysis in the static mode, the analysis of pyrolysis in a freefall reactor requires the consideration of relevant forces acting on the falling particles. Also, the particle velocity and drag force can be affected by particle properties and properties of the flowing fluid which are changing along the pyrolysis reactor. In summary, the present work aims to study the distribution and properties of pyrolysis products from three types of biomass wastes, namely, palm shell, palm kernel cake, and cassava pulp residue in a three-zone free-fall reactor as well as the kinetic modeling of the pyrolysis process.

\section{Experimental Section}

2.1. Material Characterization. Three types of biomass were studied in a laboratory free-fall pyrolysis reactor, including palm shell (PS), cassava pulp residue (CPR), and palm kernel $(\mathrm{PK})$. These raw materials were milled and sieved to obtain average particle sizes in the range from 0.18 to $1.55 \mathrm{~mm}$ for palm shell and $0.28 \mathrm{~mm}$ for palm kernel and cassava pulp residue. Each sample was dried in an electric oven at $110^{\circ} \mathrm{C}$ for $24 \mathrm{~h}$ to remove the excess moisture and kept in a desiccator for subsequent characterization and pyrolysis experiments.

Compositions of the biomass precursors were characterized by means of proximate and ultimate analyses. Proximate analysis was performed according to ASTM method to determine the weight percentage of moisture (ASTM D286795), volatile matter (ASTM D5832-95), ash content (ASTM D2866-94), and fixed carbon (by difference). Ultimate analysis, determined with a CHNS/O analyzer (Perkin Elmer PE2400 series), gives information on weight \% of carbon, nitrogen, hydrogen, sulfur, and oxygen (by difference). True and apparent densities of the test biomasses and char product were measured with a helium pycnometer (Accu Pyc 1330, Micromeritics). In addition, thermal decomposition of biomass precursors was determined with a thermogravimetric analyzer (SDT 2960 DSC-TGA model, TA Instruments), using nitrogen (99.99\% purity) as an inert carrier gas.

2.2. Flash Pyrolysis in a Free-Fall Reactor. A standard vertical tube furnace supplied by Carbolite, UK, was employed for the heating of a free-fall pyrolysis reactor. The attached alumina tube coming with the furnace has an internal diameter of $0.1 \mathrm{~m}$ and an overall length of $1.10 \mathrm{~m}$. It has a centrally heated zone of $0.20 \mathrm{~m}$ in length and the upper and lower nonheated sections of $0.45 \mathrm{~m}$ long for each section. The free-fall reactor used for the pyrolysis study, which was fabricated from

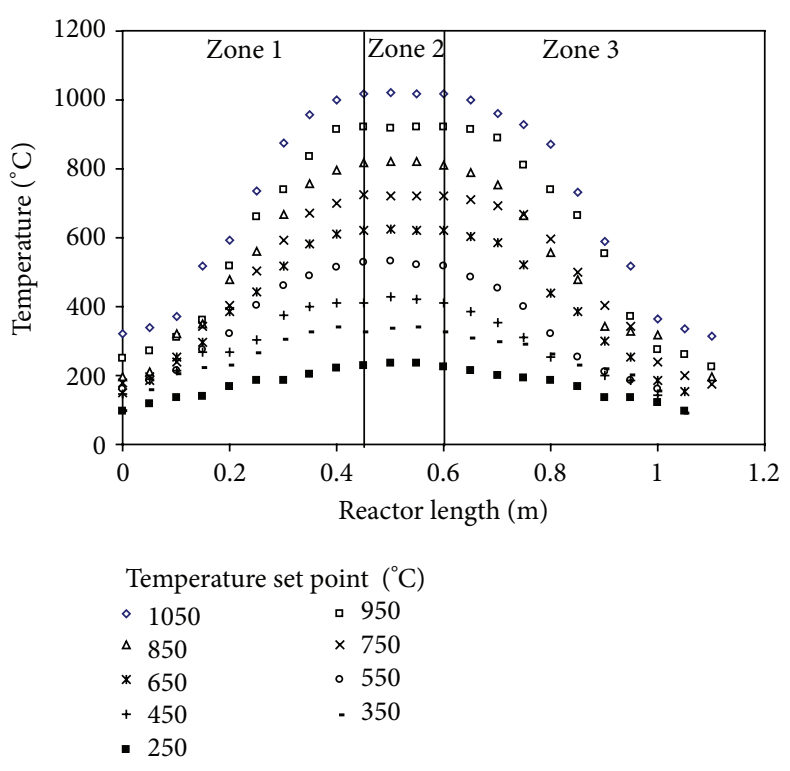

FIGURE 1: Temperature profiles in a free-fall reactor.

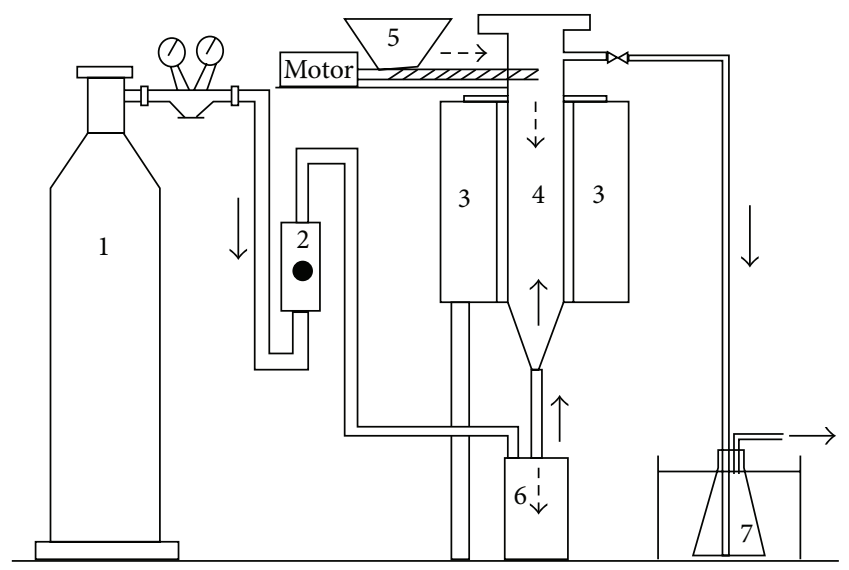
(1) Nitrogen tank cylinder
(7) Condenser
(2) Flow meter - - - Solid
(3) High temperature vertical tube furnace - Gas
(4) Stainless steel free-fall reactor
(5) Raw material feeder
(6) Solid product collector

FIGURE 2: Schematic diagram of the free-fall reactor unit.

a stainless steel pipe of $0.04 \mathrm{~m}$ I.D. and has the same length as the furnace, was inserted inside the alumina tube. Figure 1 shows the temperature profile inside the reactor for various setting temperatures of the central hot zone, starting from the top of reactor for zone I to be called preheating zone, followed by zone II (heated zone) and zone III (cooling zone), respectively. Figure 2 shows the schematic diagram of the free-fall reactor system and Table 1 lists the operating conditions used.

For each experimental run, the furnace was turned on and nitrogen gas was admitted into the reactor from the bottom and flew upward at the rate of $200 \mathrm{~cm}^{3} / \mathrm{min}$, corresponding 
TABLE 1: Experimental conditions for biomass pyrolysis study in a free-fall reactor.

\begin{tabular}{lcccc}
\hline Biomass & Temperature $\left({ }^{\circ} \mathrm{C}\right)$ & Inert gas flow rate $\left(\mathrm{cm}^{3} / \mathrm{min}\right)$ & Average particle size $(\mathrm{mm})$ & Biomass feed rate $(\mathrm{g} / \mathrm{min})$ \\
\hline PS & $250-1050$ & 200 & $0.18-1.55$ & 0.6 \\
PK & $250-1050$ & 200 & 0.28 & 0.6 \\
CPR & $250-1050$ & 200 & 0.28 & 0.6 \\
\hline
\end{tabular}

PS: palm shell, PK: palm kernel, CPR: cassava pulp residue.

to the flow velocity of $2.65 \times 10^{-3} \mathrm{~m} / \mathrm{s}$. When the desired pyrolysis temperature was reached, a batch of $50 \mathrm{~g}$ of biomass sample was continuously fed from the top into the reactor at a rate of $0.6 \mathrm{~g} / \mathrm{min}$ by a calibrated screw feeder. The char produced dropped to the bottom part of the reactor and it was collected in a solid collector. The pyrolysis vapor flew out the reactor and passed through a condenser where the liquid product and entrained solid were collected. The condenser operated at $-10^{\circ} \mathrm{C}$ using a temperature-controlled bath filled with a glycerine-water mixture. At the completion of each run, the solid and liquid products left in the condenser were separated and weighed. The total yields of liquid and char products were calculated based on the total amount of biomass fed into the system. The gas yield was estimated by mass balance knowing the total yields of both the solid and liquid products. The apparent density of final char product $\left(\rho_{p}\right)$ was estimated from the total weight of collected char and volume of a $50 \mathrm{~g}$ batch of biomass feed calculated from the apparent density of the feed particles, assuming that there is no change in the char particle volume during the course of biomass pyrolysis.

2.3. Analysis of Pyrolysis Products. Liquid products collected from palm shell pyrolysis were analyzed for physicochemical properties. Water in the biooil was removed by isotropic distillation with toluene [11]. A chemical analysis of the dewatered biooil was determined by gas chromatography (Varian CP-3800) equipped with a capillary coated with VF-5MS ( $30 \mathrm{~m} \times 0.39 \mathrm{~mm}$ and $0.25 \mu \mathrm{m}$ film thickness). In addition, the biooil derived from biomass pyrolysis was also analyzed for its calorific value (ASTM D240-92), density (Gay-Lussac bottle), viscosity (ASTM D445-96), and water by the Karl Fischer Titration.

The solid product derived from pyrolysis of palm shell was characterized for elemental analysis (CHNS/O analyzer, Perkin Elmer PE2400 series II). Proximate analysis, consisting of moisture content (ASTM D2867-95), volatile content (ASTM D5832-95), ash content (ASTM D2866-94), and fixed carbon content was also determined according to ASTM procedures. Furthermore, the true density and porous properties of char product were analyzed by using a helium pycnometer (Accupyc 1330 Micromeritics) and Autosorb-iQ (Quantachrome), respectively.

The gas product was characterized by a gas chromatograph (Varian CP-3800) equipped with a thermal conductivity detector (TCD). A capillary coated with CP-Carboplot (27.5 $\mathrm{m} \times 0.53 \mathrm{~mm}$ and $0.25 \mu \mathrm{m}$ film thickness) was used for the analysis of $\mathrm{CO}_{2}, \mathrm{CO}, \mathrm{H}_{2}$, and $\mathrm{CH}_{4}$.

\section{Modeling of Biomass Pyrolysis in a Free-Fall Reactor}

For the modeling of biomass pyrolysis, it is assumed that no particle shrinkage occurs; that is, diameter of a biomass particle remains constant during the course of pyrolysis reaction and that there is no heat and mass transfer resistances across the pyrolyzed particle. The following equations form the basis of pyrolysis modeling for a three-zone free-fall reactor studied in this work.

3.1. Equation of Particle Motion. The equation of motion for a spherical char particle settling in a flowing fluid is derived based on the conservation of momentum which states that the rate of change of momentum equals the net forces acting on the particle due to gravity, buoyancy, and drag forces. Mathematically,

$$
\begin{aligned}
\frac{\pi}{6} d_{p}^{3} \rho_{p} \frac{d\left(v_{p}-v_{g}\right)}{d t}= & \frac{1}{6} \pi d_{p}^{3}\left(\rho_{p}-\rho_{g}\right) g \\
& -\frac{1}{8} \pi \rho_{g} d_{p}^{2} C_{D}\left(v_{p}-v_{g}\right),
\end{aligned}
$$

or after rearranging,

$$
\frac{d v_{p}}{d t}=\frac{\left(\rho_{p}-\rho_{g}\right) g}{\rho_{p}}-\frac{3}{4} \frac{C_{D} \rho_{g}\left(v_{p}-v_{g}\right)^{2}}{d_{p} \rho_{p}},
$$

where $v_{p}=$ particle velocity, $\rho_{p}=$ particle apparent density (weight of particle/volume of solid and void), $d_{p}=$ particle diameter, $v_{g}=$ gas velocity, $\rho_{g}=$ gas density, $C_{D}=$ drag coefficient, a function of Reynolds number $=18 / \operatorname{Re}_{p}^{0.6}, 1 \leq$ $\operatorname{Re}_{p} \leq 1000$, and $\operatorname{Re}_{p}=$ particle Reynolds number $=d_{p}\left(v_{p}-\right.$ $\left.v_{g}\right) \rho_{g} / \mu_{g}$.

3.2. Pyrolysis Kinetic Equations. The two-parallel reaction kinetic model [9] was adopted in this work to describe the conversion of pyrolyzed particles along the vertical distance of the reactor. It is based on the assumption that a biomass consists of two major components, with weight fractions $a$ and $b$, that decompose independently into volatile and char products, according to the following rate equations:

$$
\frac{d \rho_{1}}{d t}=-A_{1} \exp \left[\frac{E_{1}}{R T}\right] \rho_{1}^{n 1},
$$




$$
\begin{gathered}
\frac{d \rho_{2}}{d t}=-A_{2} \exp \left[\frac{E_{2}}{R T}\right] \rho_{2}^{n 2}, \\
\rho_{p}=\rho_{1}+\rho_{2},
\end{gathered}
$$

where $\rho, A, E, n, R$, and $T$ are density of biomass component, the preexponential factor, activation energy, order of reaction, gas constant, and absolute temperature, respectively. Subscripts 1 and 2 refer to component 1 and 2 of the biomass, respectively. $\rho_{1}$ and $\rho_{2}$ are equal to $\rho_{p} a$ and $\rho_{p} b$, respectively, and $\rho_{p}$ represents the apparent density of a char particle. The temperature zones inside the reactor are displayed in Figure 1 which indicates that the reactor can be divided from the top of reactor into three consecutive regions: (i) preheating zone, (ii) heated zone, and (iii) cooling zone. The above kinetic expressions for the pyrolysis of the first and second components in the three hot zones of the reactor can now be written in terms of reactor length $(L)$ by employing the relation, $v_{p}-v_{g}=d L / d t$, to obtain the following.

(1) Preheating zone (Zone I):

1st component:

$$
\frac{d \rho_{1}}{\rho_{1}^{n_{1}}}=\int_{0}^{0.45}-\frac{A_{1} \exp \left[E_{1} / R T_{1}(L)\right]}{\left(v_{p}-v_{g}\right)} d L
$$

2nd component:

$$
\frac{d \rho_{2}}{\rho_{2}^{n_{2}}}=\int_{0}^{0.45}-\frac{A_{2} \exp \left[E_{2} / R T_{1}(L)\right]}{\left(v_{p}-v_{g}\right)} d L .
$$

(2) Heated zone (Zone II):

1st component:

$$
\frac{d \rho_{1}}{\rho_{1}^{n_{1}}}=\int_{0.45}^{0.60}-\frac{A_{1} \exp \left[E_{1} / R T_{2}\right]}{\left(v_{p}-v_{g}\right)} d L,
$$

2nd component:

$$
\frac{d \rho_{2}}{\rho_{2}^{n_{2}}}=\int_{0.45}^{0.60}-\frac{A_{2} \exp \left[E_{2} / R T_{2}\right]}{\left(v_{p}-v_{g}\right)} d L .
$$

(3) Cooling zone (Zone III):

1st component:

$$
\frac{d \rho_{1}}{\rho_{1}^{n_{1}}}=\int_{0.60}^{1.10}-\frac{A_{1} \exp \left[E_{1} / R T_{3}(L)\right]}{\left(v_{p}-v_{g}\right)} d L
$$

2nd component:

$$
\frac{d \rho_{2}}{\rho_{2}^{n_{2}}}=\int_{0.60}^{1.10}-\frac{A_{2} \exp \left[E_{2} / R T_{3}(L)\right]}{\left(v_{p}-v_{g}\right)} d L .
$$

The initial weight fractions of the first and second components are designated as $a$ and $b$ and the sum of the two numbers equal to unity. The apparent density of each biomass component $\left(\rho_{1}\right.$ and $\rho_{2}$ ) leaving one zone will be the initial density for the next adjacent zone. To simplify the calculation, fluid properties and fluid velocity are assumed to be constant at the average temperature of that zone. $T_{1}(L)$ and $T_{3}(L)$ are the temperature profiles of the preheating and cooling zone of the reactor, respectively. The estimation of these temperatures at various positions along the reactor is obtained directly from the reactor temperature profile as displayed in Figure 1.

The calculation scheme commences by first setting the initial values of kinetic parameters $A_{1}, A_{2}, E_{1}, E_{2}, n_{1}, n_{2}$, $a$ and $b$, and $\rho_{p}, C_{D}, \operatorname{Re}_{p}$, and $v_{p}$ for the condition at the reactor inlet. The inlet particle velocity was estimated by the equation, $v_{p \text {,initial }}=\left[(2 g / 27)\left(\rho_{p} / \rho_{f}-1\right)\right]^{5 / 7} D_{p}^{8 / 7}\left(\rho_{f} / \mu_{f}\right)^{3 / 7}$. Then, the computation is performed by numerical method to obtain the values of $\rho_{p}$ and $v_{p}$ as a function of reactor length which include those at the reactor exit, using (4)(9). The calculation is repeated to obtain an optimum set of kinetic parameters, using the nonlinear least square (NLS) algorithm to minimize the objective function defined as O.F. $=\sum_{i=1}^{N}\left(\rho_{\mathrm{cal}, i}-\rho_{\exp , i}\right)^{2}$, where $\rho_{\exp , i}$ and $\rho_{\text {cal }, i}$ represent the experimental and calculated char product density (char density at the reactor exit). Subscript $i$ denotes the discrete values of $\rho$, and $N$ is the number of data points used in the model fitting. Next, the calculated char yield is computed from the calculated char density by the following equation:

$$
\text { char yield }(\% \mathrm{wt})=100\left(\frac{\rho_{p}}{\rho_{\text {feed }}}\right),
$$

where $\rho_{p}$ and $\rho_{\text {feed }}$ are the product char density and the feed particle density, respectively.

\section{Results and Discussion}

4.1. Biomass Properties. Table 2 presents the proximate and ultimate analysis of the biomass precursors. It is seen that the biomass samples contain more than $70 \%$ of volatile matters with cassava pulp residue having the highest volatile content. The high volatile matter found in the samples suggests the high potential of these residues for energy production by pyrolysis [12]; high levels of volatile matter result in more liquid and gas fuel to be obtained from the pyrolysis process. The fixed carbon content is the carbon found in the biomass that is left after volatile matters are driven off and it is used as an estimate of the amount of solid product left after the pyrolysis of biomass [13]. The fixed carbon reported in Table 2 indicates that the solid yield of pyrolysis from palm shell is higher than those of palm kernel and cassava pulp residue. Table 2 indicates that the carbon content of biomass precursor varies from 43.08 to $49.34 \%$. Generally, higher carbon content leads to a higher heating value of solid combustion [14], thus making these biomasses to be good precursors for energy production. The results also indicate that the sulfur content in the biomass precursors is much lower than most typical fossil fuels (bituminous coal $0.5-$ $1.5 \%$, typical distillate oil $0.2-1.2 \%$ ) [15]. This suggests that 
TABLE 2: Proximate and ultimate analysis of oil-palm shell, oil-palm kernel, and cassava pulp residue and particle true densities.

\begin{tabular}{lcccccccccc}
\hline \multirow{2}{*}{ Biomass } & \multicolumn{4}{c}{ Ultimate analysis ${ }^{1},(\% \mathrm{wt})$} & \multicolumn{3}{c}{ Proximate analysis ${ }^{2},(\% \mathrm{wt})$} & \multicolumn{2}{c}{ Solid density $^{3},\left(\mathrm{~g} / \mathrm{cm}^{3}\right)$} \\
& $\mathrm{C}$ & $\mathrm{H}$ & $\mathrm{N}$ & $\mathrm{S}$ & $\mathrm{O}$ & Volatile & Fixed carbon & Ash & True density & Apparent density \\
\hline PS & 49.34 & 6.00 & 0.78 & 0.33 & 43.55 & 72.56 & 25.97 & 1.47 & 1.43 & 1.28 \\
PK & 43.84 & 6.13 & 3.11 & 0.06 & 46.86 & 79.68 & 16.78 & 3.54 & 1.40 & 1.30 \\
CPR & 43.08 & 6.10 & 0.40 & 0.07 & 50.36 & 83.86 & 12.12 & 4.02 & 1.37 & 1.13 \\
\hline
\end{tabular}

${ }^{1}$ Dry and ash-free basis.

${ }^{2}$ Dry basis.

${ }^{3}$ Particle size of $1.55 \mathrm{~mm}$.

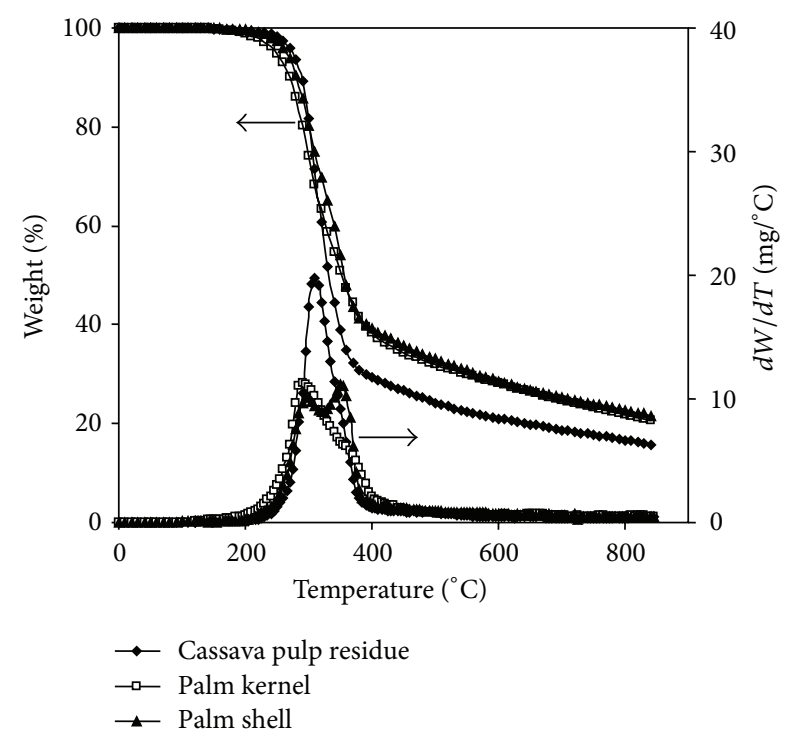

FIGURE 3: TG and DTG data of palm shell, palm kernel, and cassava pulp residue.

thermal decomposition of biomass should give lower sulfur emission than fossil fuels. The reason that biomass fuels are almost devoid of sulfur and coupled with its low ash content has made biomass a highly desirable fuel from the standpoint of pollution control cost. In addition, the composition of biomass ash which contains alkaline metals (e.g., $\mathrm{Na}, \mathrm{K}, \mathrm{Mg}$, and $\mathrm{Ca}$ ) can react with the released sulfur dioxide as well [16]. Overall, the use of biomass as a fuel creates less environmental problems. Table 2 also shows the true and apparent densities of the test biomasses.

4.2. Thermal Behavior of Biomass. In this work, TGA is used as an analytical technique to study the thermal decomposition behavior of biomass sample in an inert atmosphere of $\mathrm{N}_{2}$. The results of TGA analysis are displayed in Figure 3 which show the weight loss curves (TG) and derivative thermogravimetric (DTG) evolution profiles as a function of heating temperature. As can be observed from TGA results, the cassava pulp residue started to decompose first followed by palm kernel and palm shell. Thermal decomposition of the biomass precursors started at approximately $250^{\circ} \mathrm{C}$, possibly by the liberation of inherent moisture. Then it was followed by a major loss of weight where the main devolatilization occurs over the temperature range from 250 to $400^{\circ} \mathrm{C}$. Further observation indicates that cassava pulp residue and palm kernel showed one DTG peak while palm shell exhibited a two peak characteristic. This is attributed to the differences in the cellulosic composition of the biomass and the pyrolysis behavior of each biomass component. Typically, hemicellulose decomposition occurs over the temperature of 200$260^{\circ} \mathrm{C}$ [17], cellulose between 240 and $350^{\circ} \mathrm{C}$ [18], and lignin decomposes when heated over the wider range of $280-500^{\circ} \mathrm{C}$ [17].

4.3. Pyrolysis in a Free-Fall Reactor. On studying the effect of pyrolysis temperature and particle size, the experiments were conducted on palm shell with nine different pyrolysis temperatures (heated zone temperature) and six different particle size ranges under a fixed sweep gas flow rate of $200 \mathrm{~cm}^{3} / \mathrm{min}$. For the effect of biomass type, the experiments were performed with different precursors under a fixed sweep gas flow rate of $200 \mathrm{~cm}^{3} / \mathrm{min}$ and particle size of $0.28 \mathrm{~mm}$.

Figure 4 shows the final solid, liquid, and gas yields derived from palm shell pyrolysis expressed as a fraction of the initial sample weight for different particle sizes and pyrolysis temperatures. For all particle sizes, the solid yields continuously decreased as the temperature was increased (see Figure 4(a)). At a high pyrolysis temperature, the solid yields tended to become constant approaching the value of $15 \%$ except for the particle size greater than $0.36 \mathrm{~mm}$ and the highest conversion is achieved for the smallest size particles. Also, the thermal decomposition of a small particle size started at the lower pyrolysis temperature than that of a larger particle size. Moreover, at a fixed pyrolysis temperature, the solid yield increased with increasing in particle size. This can be explained by the fact that a larger size particle has a greater temperature gradient due to the longer heat diffusional path. This effect leads to a lower average particle temperature and hence giving less solid conversion by the pyrolysis reaction. As a result of this behavior, to cover a wide range of solid yield or solid conversion for large particle size, it is necessary to extend the length of heated zone of the reactor to allow sufficient time for increased solid decomposition.

Figure 4(b) shows the effect of palm shell particle size and pyrolysis temperature on the yields of liquid product. The liquid yield increased with the increasing of pyrolysis temperature and passed through a maximum at temperature around $650^{\circ} \mathrm{C}$ for particle size of $0.18 \mathrm{~mm}$ and at $750^{\circ} \mathrm{C}$ for particle size in the range of $0.23-0.36 \mathrm{~mm}$. For particle size larger than $0.36 \mathrm{~mm}$, the liquid yield tended to increase continuously with increasing pyrolysis temperature. The decrease 


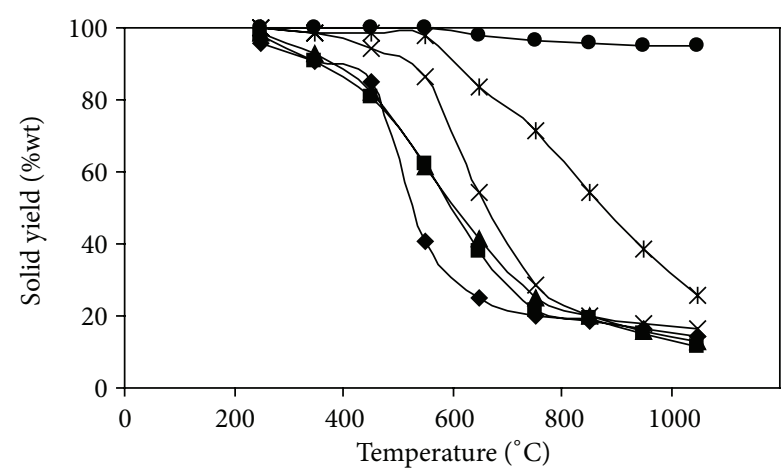

(a)

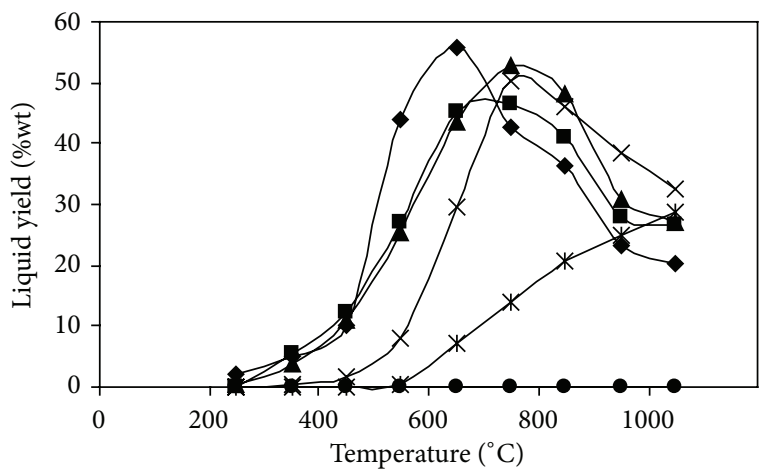

(b)

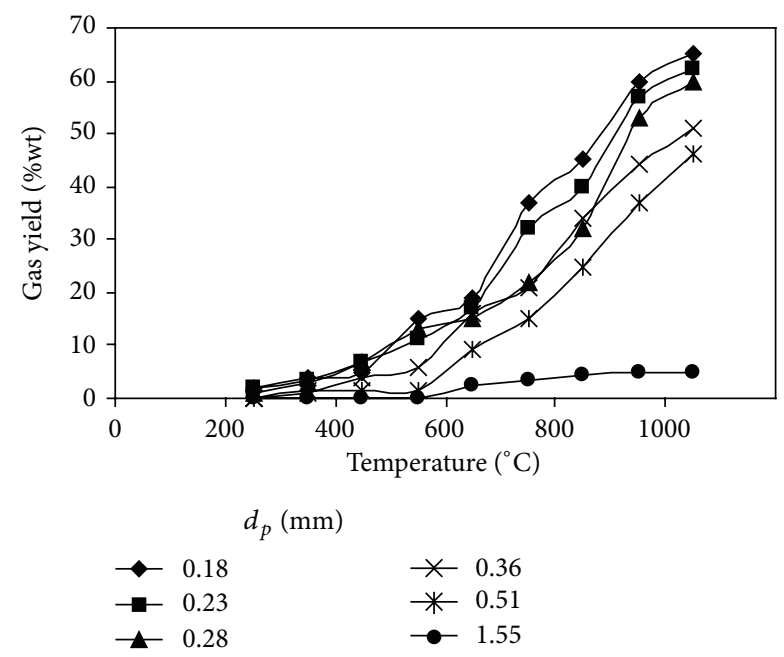

(c)

FIGURE 4: Effect of particle size and pyrolysis temperature on (a) solid yield, (b) liquid yield, and (c) gas yield (palm shell feed rate $0.6 \mathrm{~g} / \mathrm{min}$ and sweep gas flow rate $200 \mathrm{~cm}^{3} / \mathrm{min}$ ).

in liquid yield and the corresponding increase in gas yield (see Figure 4(c)) above the optimum pyrolysis temperature are probably caused by the decomposition of some liquid vapors in the gas product. It is also noted that there was no liquid product being produced from the pyrolysis of the largest size of $1.55 \mathrm{~mm}$ at the temperature below $1000^{\circ} \mathrm{C}$.

From Figure 4(c), it is seen that higher pyrolysis temperature and small particle size led to more volatilization resulting in higher yield of gaseous products. The increase in gaseous products is believed to be predominantly due to secondary cracking of the pyrolysis vapors at higher temperatures [19]. At high pyrolysis temperatures both the rate of primary pyrolysis and the rate of thermal cracking of tar to gaseous products are expectedly high. Further, a smaller particle is expected to produce higher gas yield because of the higher heat up rate and heat flux as compared to the larger particles. This observation agrees with the work of Wei et al. (2006) [20] who studied the effect of particle size on product distribution from pyrolysis of pine sawdust and apricot stone in a free-fall reactor at $800^{\circ} \mathrm{C}$. They reported that the decrease of biomass particle size contributed to an increase in the gas yields.

Figure 5(a) compares the solid yields from pyrolysis of palm shell, palm kernel, and cassava pulp residue at various pyrolysis temperatures. The cassava pulp residue started to decompose at a lower pyrolysis temperature than palm kernel and palm shell. These results are also consistent with the results from the TGA analysis (Figure 2). It was also found that the thermal decomposition behavior of biomass was consistent with the amount of volatile matter content. Biomass with a high volatile matter can be easily decomposed by heating than that with lower volatile content. Therefore, cassava pulp residue which has the highest amount of volatile matter $(83.86 \mathrm{wt} \%)$ could decompose more rapidly than palm kernel (79.62 wt\%) and palm shell (72.56 wt\%). The yield of liquid product (Figure 5(b)) was found to increase with pyrolysis temperature to give a maximum value at around $400^{\circ} \mathrm{C}$ for cassava pulp residue and at $520^{\circ} \mathrm{C}$ for palm shell and palm kernel, and then it decreased with increasing in pyrolysis temperature. The decrease in liquid yields and the corresponding increase in gas yields above the optimum temperature (see Figure 5(c)) are probably due to secondary cracking of the pyrolysis vapor at relatively high temperatures [21]. Furthermore, the secondary decomposition of the char at higher temperatures may as well give additional noncondensable gaseous product [22]. Figure 5(c) shows that the gas yield increased over the whole temperature range and the pyrolysis of cassava pulp residue gave higher gas product than those of palm kernel and palm shell. This is probably due to the differences in cellulosic components of these biomasses. The cellulose and hemicellulose components of biomass are mainly responsible for the volatile portion of the pyrolysis products while lignin is the main contributor to the formation of char [21].

Typical characteristics of char, liquid, and gas product derived from palm shell pyrolysis at temperature of $650^{\circ} \mathrm{C}$, $\mathrm{N}_{2}$ flow rate of $200 \mathrm{~cm}^{3} / \mathrm{min}$, particle size of $0.28 \mathrm{~mm}$, and feed rate of $0.6 \mathrm{~g} / \mathrm{min}$ are listed in Table 3 . Proximate analysis indicates that the main component in char is fixed carbon. It may be that during pyrolysis, hydrogen and oxygen were consumed via reactions of dehydrogenation and deoxygenation to produce $\mathrm{CO}_{2}, \mathrm{CO}, \mathrm{H}_{2}, \mathrm{H}_{2} \mathrm{O}$ [23]. This should cause the decrease in the molar ratio of $\mathrm{H} / \mathrm{C}$ and $\mathrm{O} / \mathrm{C}$ in char. Calorific value of the derived char is $29.87 \mathrm{MJ}$ which is comparable to that of coal $(\sim 35 \mathrm{MJ})$ [24]. Porous characteristics of char indicates that the derived char has reasonable BET surface 
TABle 3: Properties of chars, liquid, and gas products derived from palm shell pyrolysis at temperature of $650^{\circ} \mathrm{C}, \mathrm{N}_{2}$ flow rate of $200 \mathrm{~cm}^{3} / \mathrm{min}$, particle size of $0.28 \mathrm{~mm}$, and feed rate of $0.6 \mathrm{~g} / \mathrm{min}$.

\begin{tabular}{|c|c|}
\hline Properties & Value \\
\hline \multicolumn{2}{|c|}{ Char product } \\
\hline \multicolumn{2}{|c|}{ Proximate analysis (dry basis) (wt\%) } \\
\hline Volatile & 20.22 \\
\hline Fixed carbon & 69.97 \\
\hline Ash & 9.82 \\
\hline \multicolumn{2}{|c|}{ Elemental analysis (dry and ash-free basis) (wt\%) } \\
\hline $\mathrm{C}$ & 59.28 \\
\hline $\mathrm{H}$ & 1.67 \\
\hline $\mathrm{O}$ & 37.52 \\
\hline $\mathrm{N}$ & 1.53 \\
\hline $\mathrm{H} / \mathrm{C}$ (mole ratio) & 0.20 \\
\hline $\mathrm{O} / \mathrm{C}$ (mole ratio) & 0.47 \\
\hline Calorific value (MJ/kg) & 29.87 \\
\hline \multicolumn{2}{|l|}{ Porous characteristics } \\
\hline BET surface area $\left(\mathrm{m}^{2} / \mathrm{g}\right)$ & 200 \\
\hline Micropore area $\left(\mathrm{m}^{2} / \mathrm{g}\right)$ & 182 \\
\hline Average pore size (nm) & 2.03 \\
\hline Total pore volume $\left(\mathrm{cm}^{3} / \mathrm{g}\right)$ & 0.111 \\
\hline Micropore volume $\left(\mathrm{cm}^{3} / \mathrm{g}\right)$ & 0.091 \\
\hline \multicolumn{2}{|c|}{ Liquid product } \\
\hline Viscosity at $40^{\circ}(\mathrm{cP})$ & 3.5 \\
\hline Density at $30^{\circ} \mathrm{C}\left(\mathrm{g} / \mathrm{cm}^{3}\right)$ & 1.16 \\
\hline $\mathrm{pH}$ & 2.67 \\
\hline Calorific value (MJ/kg) & $5.8\left(35.3^{*}\right)$ \\
\hline Water contents (wt \%) & 51 \\
\hline $\mathrm{n}$-Octane, $\mathrm{C}_{8}(\mathrm{wt} \%)$ & 2.542 \\
\hline Phenol (wt\%) & 1.987 \\
\hline Furfural (wt\%) & 0.876 \\
\hline Benzene (wt\%) & 0.386 \\
\hline Toluene (wt\%) & 0.712 \\
\hline Xylene (wt\%) & 0.364 \\
\hline Styrene (wt\%) & 0.128 \\
\hline \multicolumn{2}{|c|}{ Gas product } \\
\hline CO (\%) & 18.13 \\
\hline $\mathrm{CO}_{2}(\%)$ & 10.10 \\
\hline $\mathrm{CH}_{4}(\%)$ & 4.21 \\
\hline $\mathrm{H}_{2}(\%)$ & 1.67 \\
\hline
\end{tabular}

${ }^{*}$ Water removed.

area of around $200 \mathrm{~m}^{2} / \mathrm{g}$ and contains mainly microspores which account for about $80 \%$ of the total pore volume.

Crude biooil displayed opaque dark color and gave the single phase chemical solution. Density of crude biooil $\left(1.16 \mathrm{~g} / \mathrm{cm}^{3}\right)$ is denser than that of diesel fuel $\left(0.78 \mathrm{~g} / \mathrm{cm}^{3}\right)$ and heavy fuel oil $\left(0.85 \mathrm{~g} / \mathrm{cm}^{3}\right)$. The crude biooil shows relatively low viscosity characteristic of $3.5 \mathrm{cP}$ at $40^{\circ} \mathrm{C}$. The low viscosity is associated with the high value of water content (51 wt\%) present in the crude biooil. Generally, the water content in biooil is mainly derived from the decomposition of ligninderived materials [25]. The crude biooil shows a high acid

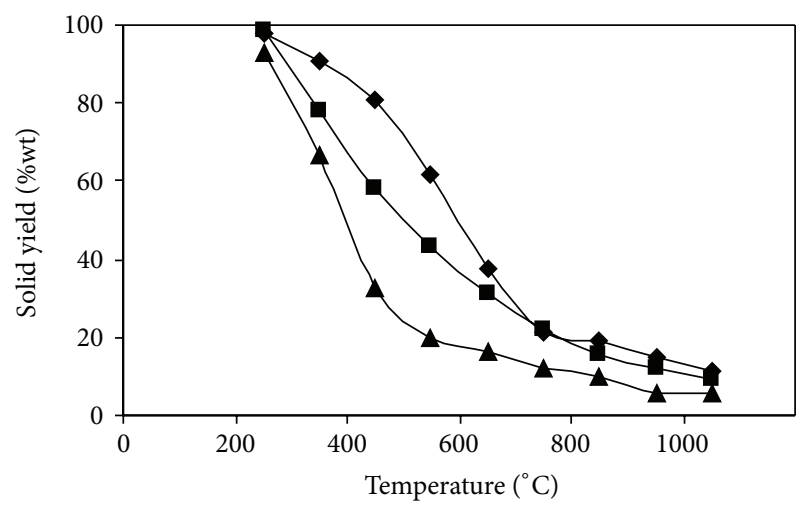

(a)

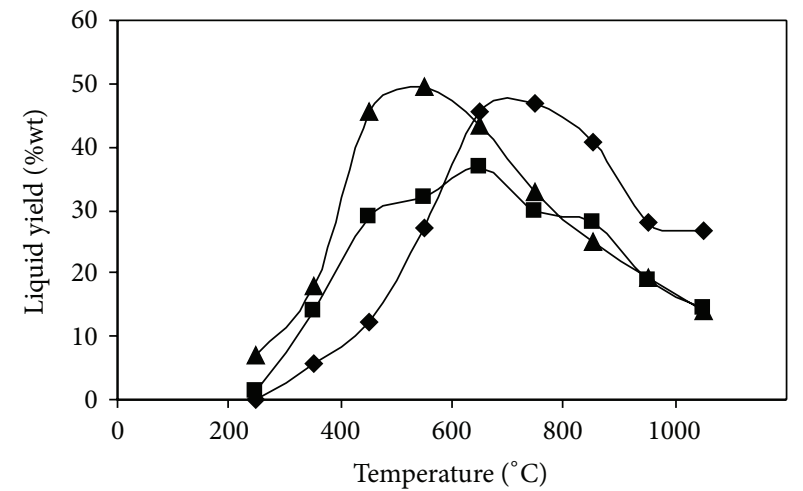

(b)

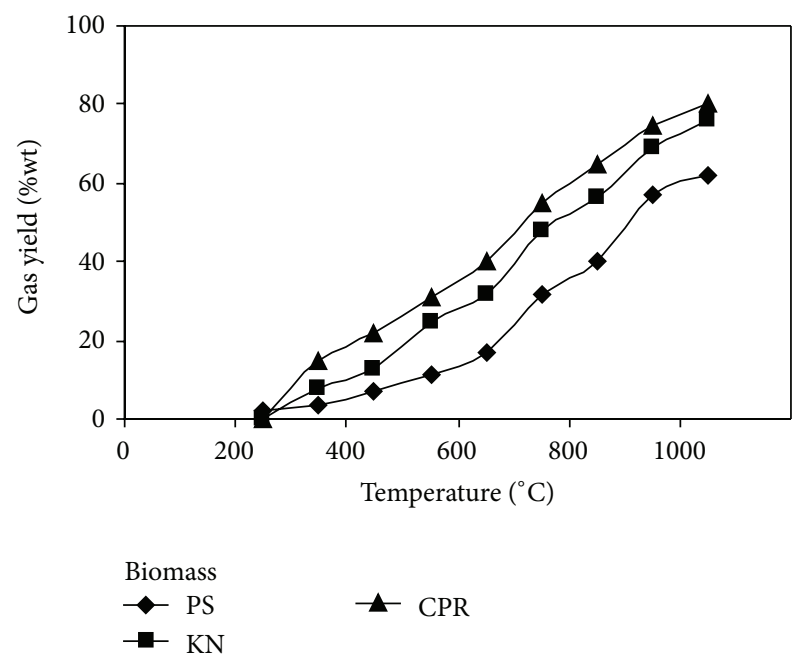

(c)

FIGURE 5: Effect of biomass type and pyrolysis temperature on (a) solid yield, (b) liquid yield, and (c) gas yield (biomass feed rate $0.6 \mathrm{~g} / \mathrm{min}$, sweep gas flow rate $200 \mathrm{~mL} / \mathrm{min}$, and particle size of $0.28 \mathrm{~mm})$.

level; $\mathrm{pH}$ at room temperature is about 2.67. It has been reported that biooil with low $\mathrm{pH}$ is very corrosive to the metals [26]. The corrosiveness of biooils is more severe when the water content is high and also when biooils are used at a high temperature [27]. In addition, removing of water from the crude biooil gave rise to an increase in calorific value from 

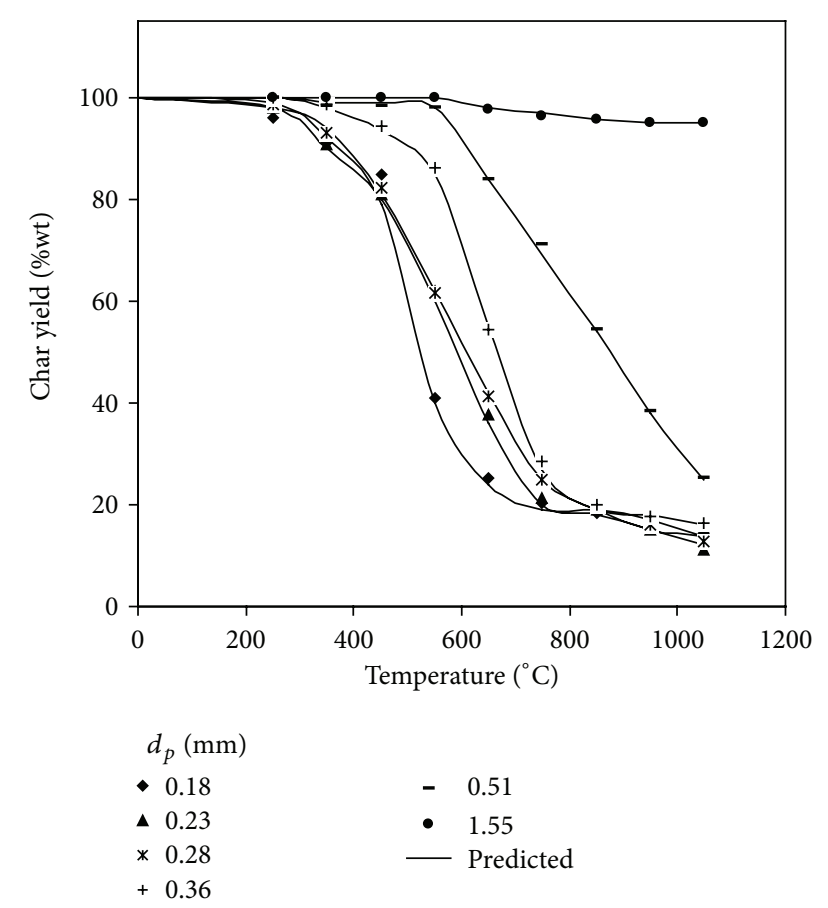

FIGURE 6: Char yields for palm shell pyrolysis in a free-fall reactor at different pyrolysis temperatures for various particle sizes $\left(\mathrm{N}_{2}\right.$ flow rate is $200 \mathrm{~cm}^{3} / \mathrm{min}$ ).

5.8 to $35.3 \mathrm{MJ} / \mathrm{kg}$. According to these results, the removal of water from biooil still gives calorific value lower than that of commercial diesel oil fuel (45.0 MJ/kg) [28]. GC analysis results show that the derived biooil provides a source of potential chemical feedstock such as octane, phenol, furfural, benzene, toluene, xylene, and styrene. As shown in Table 3, the gas products consist of $\mathrm{CO}, \mathrm{CO}_{2}, \mathrm{CH}_{4}$, and $\mathrm{H}_{2}$ with $\mathrm{CO}$ being the dominant components among the others.

4.4. Kinetics of Biomass Pyrolysis. Figures 6 and 7 compare the model predicted and experimental char yields as a function of heated zone temperature for varying initial particle sizes and types of biomass, respectively. Excellent agreement between the experimental data and the model prediction is discernible. The kinetic parameters $(E, A$ and $n)$, maximum error, and correlation coefficient $\left(R^{2}\right)$ estimated from the model are summarized in Table 4. It was found that for all conditions, the values of the correlation coefficient are higher than 0.99 and with the maximum error of estimate being less than $7.2 \%$. This proves that the pyrolysis model proposed in this study can be used to describe the thermal decomposition behaviors of the test biomasses in a free-fall reactor within acceptable accuracy.

As observed from Table 4, the first component appears to have higher activation energy $\left(E_{1}\right)$ than that of the second component $\left(E_{2}\right)$. This indicates that the first component requires a larger amount of energy to initiate the pyrolysis reaction as compared to the second component. Also, the first biomass component has higher value of the preexponential factor. In addition, the larger value of $b$ in comparison with

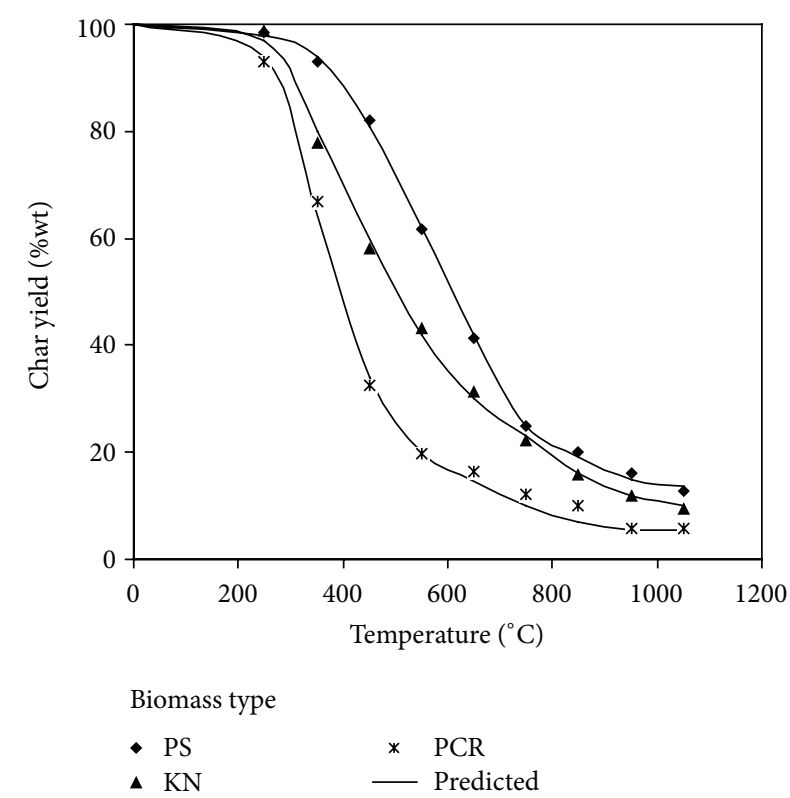

FIGURE 7: Char yields of biomass pyrolysis for different pyrolysis temperatures (particle size is $0.28 \mathrm{~mm}$ and $\mathrm{N}_{2}$ flow rate is $200 \mathrm{~cm}^{3} / \mathrm{min}$ ).

that of $a$ signifies that the decomposition of biomass precursor should be contributed predominantly by the second component. For this work, the lignocellulosic component of biomass has been analyzed by the Kurschner-Hoffer method for holocellulose extraction and the Klason method for lignin determination [29]. It has been found that palm shell contains $45.42 \%$ cellulose, $21.74 \%$ hemicellulose, and $17.64 \%$ lignin; palm kernel contains $30.4 \%$ cellulose, $25.12 \%$ hemicellulose, and $15.72 \%$ lignin; and cassava pulp residue contains $15.6 \%$ cellulose, $4.6 \%$ hemicellulose, and 2.2\% lignin. Based solely on these data, it could be inferred that the first component (smaller weight fraction) is probably contributed by lignin, and the second component (larger weight fraction) by both the cellulose and hemicellulose.

It is further observed that, for palm shell pyrolysis, the kinetic parameters ( $n, A$ and $E$ ) appear to vary with particle size but showing no definite trend. In principle, the kinetic parameters should be constant and independent of particle size if the pyrolysis process is indeed a true kinetic control. This observed inconsistency probably results from the influence of heat and mass transfer limitations which are not taken into account by the present pyrolysis model.

The variation of char yield of the three biomass precursors with pyrolysis temperature is illustrated in Figure 7. Over the pyrolysis temperature range studied, the char yield of cassava pulp residue was lower than those of palm kernel and palm shell. This indicates that cassava pulp residue should decompose more rapidly than both palm kernel and palm shell. This result is consistent with the much lower values of activation energies $\left(E_{1}\right.$ and $\left.E_{2}\right)$ of cassava pulp residue compared to those of palm shell and palm kernel pyrolysis, as shown in Table 4 . 
TABLE 4: Estimated kinetic parameters of biomass pyrolysis in a free-fall reactor.

\begin{tabular}{lccccccccccc}
\hline Biomass & Size $(\mathrm{mm})$ & $a$ & $A_{1}\left(\mathrm{~s}^{-1}\right)$ & $E_{1}(\mathrm{~kJ} / \mathrm{mol})$ & $n_{1}$ & $b$ & $A_{2}\left(\mathrm{~s}^{-1}\right)$ & $E_{2}(\mathrm{~kJ} / \mathrm{mol})$ & $n_{2}$ & Max. error (\%) & Correlation coefficient $\left(R^{2}\right)$ \\
\hline & 0.18 & $2.73 \times 10^{4}$ & 556 & 1.00 & $8.63 \times 10^{4}$ & 123 & 3.00 & 7.16 & 0.9958 \\
& 0.23 & & $2.75 \times 10^{4}$ & 500 & 1.30 & $7.90 \times 10^{4}$ & 124 & 2.95 & 6.95 & 0.9955 \\
PS & 0.28 & 0.14 & $1.02 \times 10^{5}$ & 650 & 3.00 & 0.86 & $2.00 \times 10^{4}$ & 129 & 2.80 & 6.40 & 0.9997 \\
& 0.36 & $5.50 \times 10^{5}$ & 473 & 6.50 & $1.88 \times 10^{3}$ & 150 & 2.94 & 5.79 & 0.9976 \\
& 0.51 & $5.80 \times 10^{5}$ & 600 & 6.40 & $1.09 \times 10^{4}$ & 152 & 6.5 & 3.13 & 0.9939 \\
& 1.55 & $6.30 \times 10^{4}$ & 640 & 4.30 & $1.90 \times 10^{4}$ & 149 & 3.00 & 0.62 & 0.9961 \\
\hline PK & 0.28 & 0.18 & $7.56 \times 10^{4}$ & 630 & 9.20 & 0.82 & $1.26 \times 10^{4}$ & 107 & 2.98 & 6.27 & 0.9925 \\
\hline CPR & 0.28 & 0.08 & $3.48 \times 10^{4}$ & 520 & 9.70 & 0.90 & $4.90 \times 10^{4}$ & 100 & 3.10 & 5.17 & 0.9993 \\
\hline
\end{tabular}

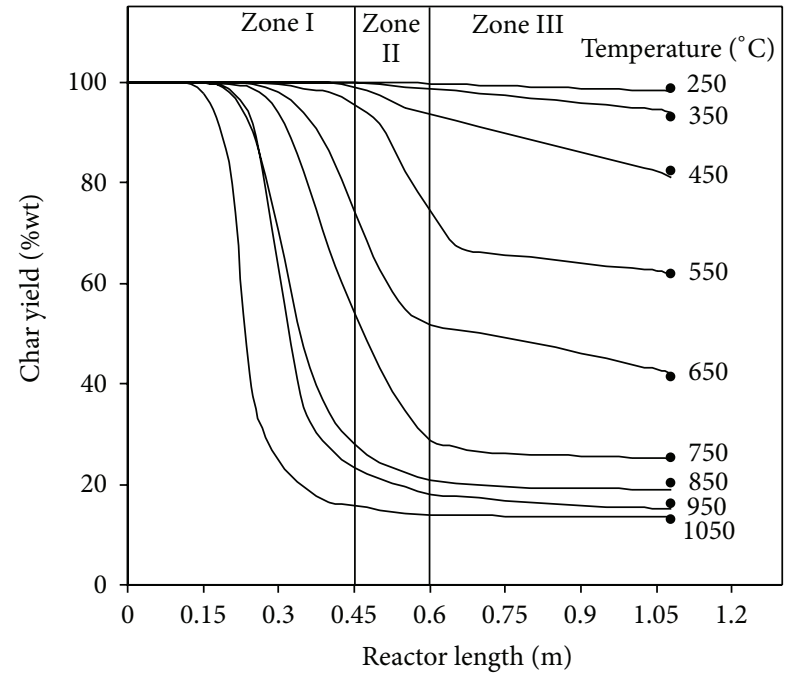

FIGURE 8: Char yields calculated from the pyrolysis model for palm shell at the average particle size of $0.28 \mathrm{~mm}$ and $\mathrm{N}_{2}$ flow rate $200 \mathrm{~cm}^{3} / \mathrm{min}$ (line is by simulation and dot represents experimental data).

Based on the obtained kinetic parameters, the predicted profiles of char yield from palm shell pyrolysis versus the length of the free-fall reactor are calculated and presented in Figure 8. As seen, palm shell $(0.28 \mathrm{~mm}$ in size) starts to decompose in the first zone and appears to reach the completion of devolatilization in the second zone of the reactor for pyrolysis above $650^{\circ} \mathrm{C}$. Also, the decomposition of biomass precursor does not occur at a relatively low pyrolysis temperature of $250^{\circ} \mathrm{C}$ at which only $1 \%$ reduction in the char yield is observed.

The relationship between the flow regime and the characteristics of char product as influenced by the pyrolysis process can be further examined by plotting particle Reynolds number $\left(\operatorname{Re}_{p}=d_{p}\left(v_{p}-v_{g}\right) \rho_{g} / \mu_{g}\right)$ versus Archimedes number $\left(\mathrm{Ar}=g \rho_{g}\left(\rho_{p}-\rho_{g}\right) d_{p}^{3} / \mu_{f}^{2}\right)$, as delineated in Figure 9. The pyrolysis behavior of biomass with reference to particle motion can be divided into three separate regimes. For small particle size $\left(d_{p}<0.36 \mathrm{~mm}\right)$, the relatively low values of $\operatorname{Re}_{p}$ and Ar are found in this zone. This indicates a large reduction of char particle density which in turn affects the velocity of biomass particle. The values of $\mathrm{Ar}$ and $\mathrm{Re}_{p}$ in this zone are lower than unity which indicate that viscous force acting on

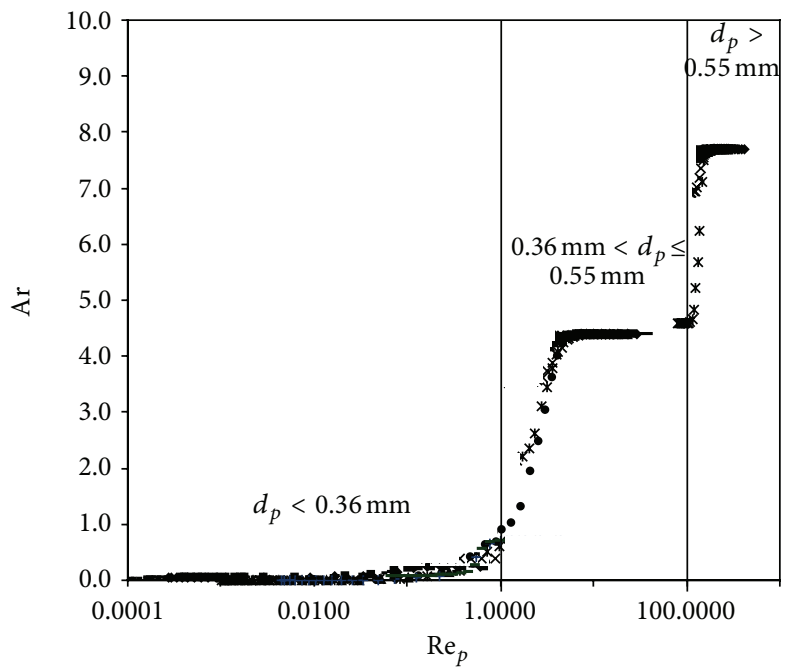

FIGURE 9: The relationship between particle Reynolds number and Archimedes number for biomass pyrolysis in a three-zone free-fall reactor.

the particle is much larger than gravity force, thus rendering the particle to move slowly. The slow moving particles will experience a long residence time in the reactor, resulting in the high weight loss of particles. In the intermediate zone for $d_{p}=0.36-0.55 \mathrm{~mm}$, the Archimedes number rises continuously with approximately fivefold increase for about an order of magnitude increase of Reynolds number from 1 to about 10, and remains substantially constant up to the Reynolds number of 100. In the last zone for $d_{p}>$ $0.55 \mathrm{~mm}$, the Archimedes number increases markedly over a small increase of Reynolds number before finally attaining a constant value of around 7.5. The extent of pyrolysis reaction for a relatively large size particle is much reduced by the rapid settling of particles that does not allow sufficient time for complete devolatilization to occur.

\section{Conclusions}

The pyrolysis temperature, particle size, and type of biomass precursor had a significant effect on the yields and properties of pyrolysis products in a three-zone free-fall reactor. It was observed that the thermal decomposition of biomass did not occur when the biomass particle was larger than $1.55 \mathrm{~mm}$ due to a relatively short central heated zone of $20 \mathrm{~cm}$ in length. 
For the biooil product, its yield increased continuously with the increase in pyrolysis temperature and passed through a maximum when an optimum temperature was reached. Typical biooil from palm shell pyrolysis is less attractive to be used as a direct fuel, due to its high water content, low calorific value, and a high acid level $(\mathrm{pH}=2.67)$. The derived solid product (char) had reasonably high calorific value $29.87 \mathrm{MJ} / \mathrm{kg}$ comparable to that of coal $(\sim 35 \mathrm{MJ} / \mathrm{kg})$ and showed reasonable BET surface area of about $200 \mathrm{~m}^{2} / \mathrm{g}$. The gas product contained $\mathrm{CO}, \mathrm{CO}_{2}, \mathrm{CH}_{4}$, and $\mathrm{H}_{2}$ with $\mathrm{CO}$ being the dominant component. The pyrolysis model developed for the free-fall reactor in the present study predicted extremely well the char yields under all pyrolysis conditions studied.

\section{Conflict of Interests}

The authors declare that there is no conflict of interests regarding the publication of this paper.

\section{Acknowledgment}

This research was funded by the Ministry of Science and Technology of Thailand.

\section{References}

[1] P. McKendry, "Energy production from biomass (part 2): conversion technologies," Bioresource Technology, vol. 83, no. 1, pp. 47-54, 2002.

[2] A. K. Jain, S. K. Sharma, and D. Singh, Reaction Kinetics of Paddy Husk Thermal Decomposition, Energy Research Center Panjab University, Panjab, India, 1996.

[3] C. Acikgoz, O. Onay, and O. M. Kockar, "Fast pyrolysis of linseed: product yields and compositions," Journal of Analytical and Applied Pyrolysis, vol. 71, no. 2, pp. 417-429, 2004.

[4] W. T. Tsai, M. K. Lee, and Y. M. Chang, "Fast pyrolysis of rice husk: product yields and compositions," Bioresource Technology, vol. 98, no. 1, pp. 22-28, 2007.

[5] Natural Resources Management and Environment Department, "Integrated Energy System in China-The Cold Northeastern Region Experience," http://www.fao.org/docrep/T4470E/ T4470E00.htm.

[6] J. Lehto, "Determination of kinetic parameters for Finnish milled peat using drop tube reactor and optical measurement techniques," Fuel, vol. 86, no. 12-13, pp. 1656-1663, 2007.

[7] M. J. Safi, I. M. Mishra, and B. Prasad, "Global degradation kinetics of pine needles in air," Thermochimica Acta, vol. 412, no. 1-2, pp. 155-162, 2004.

[8] N. Nugranad, Pyrolysis of biomass [Ph.D. thesis], University of Leeds Department of Fuel and Enegy, 1997.

[9] P. Luangkiattikhun, C. Tangsathitkulchai, and M. Tangsathitkulchai, "Non-isothermal thermogravimetric analysis of oil-palm solid wastes," Bioresource Technology, vol. 99, no. 5, pp. 986-997, 2008.

[10] S. Hu, A. Jess, and M. Xu, "Kinetic study of Chinese biomass slow pyrolysis: comparison of different kinetic models," Fuel, vol. 86, no. 17-18, pp. 2778-2788, 2007.

[11] E. G. Baker and D. C. Elliott, "Catalytic hydrotreating of biomass-derived oil," in Pyrolysis Oils From Viomass, American Chemical Society, 1988.
[12] Q. Wu, J. Dai, Y. Shiraiwa, G. Sheng, and J. Fu, "A renewable energy source-hydrocarbon gases resulting from pyrolysis of the marine nanoplanktonic alga Emiliania huxleyi," Journal of Applied Phycology, vol. 11, no. 2, pp. 137-142, 1999.

[13] M. Hutagalung, "Understanding coal analysis," Majari Magazine, 2008, http://majarimagazine.com/2008/06/understandingcoal-sample-analysis/.

[14] A. Demirbas, "Combustion characteristics of different biomass fuels," Progress in Energy and Combustion Science, vol. 30, no. 2, pp. 219-230, 2004.

[15] B. R. Miller, "Structure of Wood," http://www.fpl.fs.fed.us/document/fplgtr/fplgtr113/ch02.pdf.

[16] M. V. Dagaonkar, A. A. C. M. Beenackers, and V. G. Pangarkar, "Enhancement of gas-liquid mass transfer by small reactive particles at realistically high mass transfer coefficients: absorption of sulfur dioxide into aqueous slurries of $\mathrm{Ca}(\mathrm{OH})_{2}$ and $\mathrm{Mg}(\mathrm{OH})_{2}$ particles," Chemical Engineering Journal, vol. 81, no. 1-3, pp. 203-212, 2001.

[17] M. J. Prins, K. J. Ptasinski, and F. J. J. G. Janssen, "Torrefaction of wood. Part 1. Weight loss kinetics," Journal of Analytical and Applied Pyrolysis, vol. 77, no. 1, pp. 28-34, 2006.

[18] J. B. Wooten, J. I. Seeman, and M. R. Hajaligol, "Observation and characterization of cellulose pyrolysis intermediates by $13 \mathrm{C}$ CPMAS NMR. A new mechanistic model," Energy and Fuels, vol. 18, no. 1, pp. 1-15, 2004.

[19] D. Mohan, C. U. Pittman Jr., and P. H. Steele, "Pyrolysis of wood/biomass for bio-oil: a critical review," Energy and Fuels, vol. 20, no. 3, pp. 848-889, 2006.

[20] L. Wei, S. Xu, L. Zhang et al., "Characteristics of fast pyrolysis of biomass in a free fall reactor," Fuel Processing Technology, vol. 87, no. 10, pp. 863-871, 2006.

[21] O. Onay and O. M. Koçkar, "Pyrolysis of rapeseed in a free fall reactor for production of bio-oil," Fuel, vol. 85, no. 12-13, pp. 1921-1928, 2006.

[22] A. H. Patrick and T. Williams, "Influence of temperature on the products from the flash pyrolysis of biomass," Fuel, vol. 75, no. 9, pp. 1051-1059, 1996.

[23] B. B. Uzun, A. E. Pütün, and E. Pütün, "Fast pyrolysis of soybean cake: product yields and compositions," Bioresource Technology, vol. 97, pp. 569-576, 2006.

[24] E. Jorjani, J. C. Hower, S. Chehreh Chelgani, M. A. Shirazi, and S. Mesroghli, "Studies of relationship between petrography and elemental analysis with grindability for Kentucky coals," Fuel, vol. 87, no. 6, pp. 707-713, 2008.

[25] F. Abnisa, W. M. A. Wan Daud, W. N. W. Husin, and J. Sahu, "Utilization possibilities of palm shell as a source of biomass energy in Malaysia by producing bio-oil in pyrolysis process," Biomass and Bioenergy, vol. 35, no. 5, pp. 1863-1872, 2011.

[26] E. Hu, Y. Xu, X. Hu, L. Pan, and S. Jiang, "Corrosion behaviors of metals in biodiesel from rapeseed oil and methanol," Renewable Energy, vol. 37, no. 1, pp. 371-378, 2012.

[27] S. Czernik, Environment Health and Safety in Fast Pyrolysis of Biomass, vol. 1, CPL Press, Newbury, UK, 1999.

[28] H. E. Saleh, "The preparation and shock tube investigation of comparative ignition delays using blends of diesel fuel with biodiesel of cottonseed oil," Fuel, vol. 90, no. 1, pp. 421-429, 2011.

[29] C. D. Blasi, G. Signorelli, C. D. Russo, and G. Rea, "Product distribution from pyrolysis of wood and agricultural residues," Industrial and Engineering Chemistry Research, vol. 38, no. 6, pp. 2216-2224, 1999. 

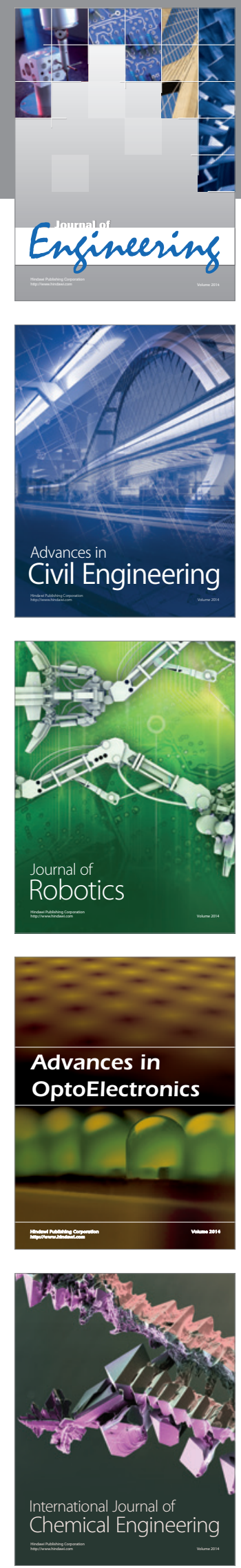

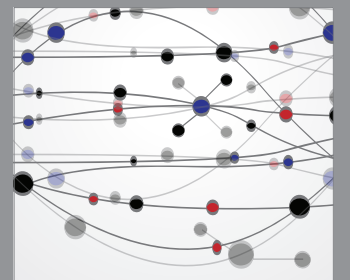

The Scientific World Journal
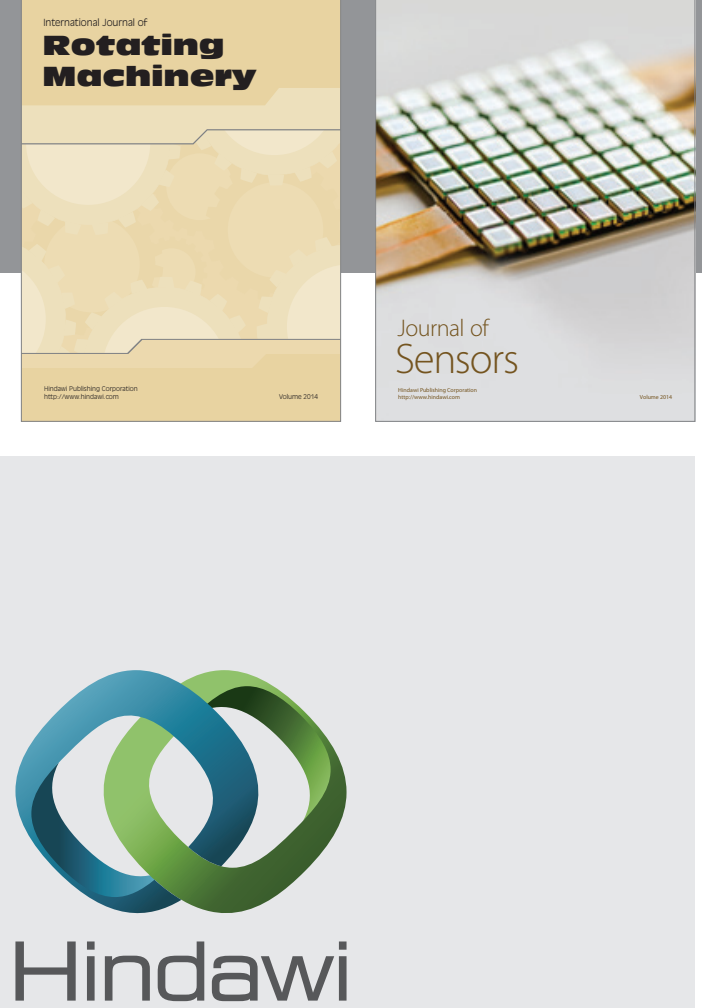

Submit your manuscripts at http://www.hindawi.com
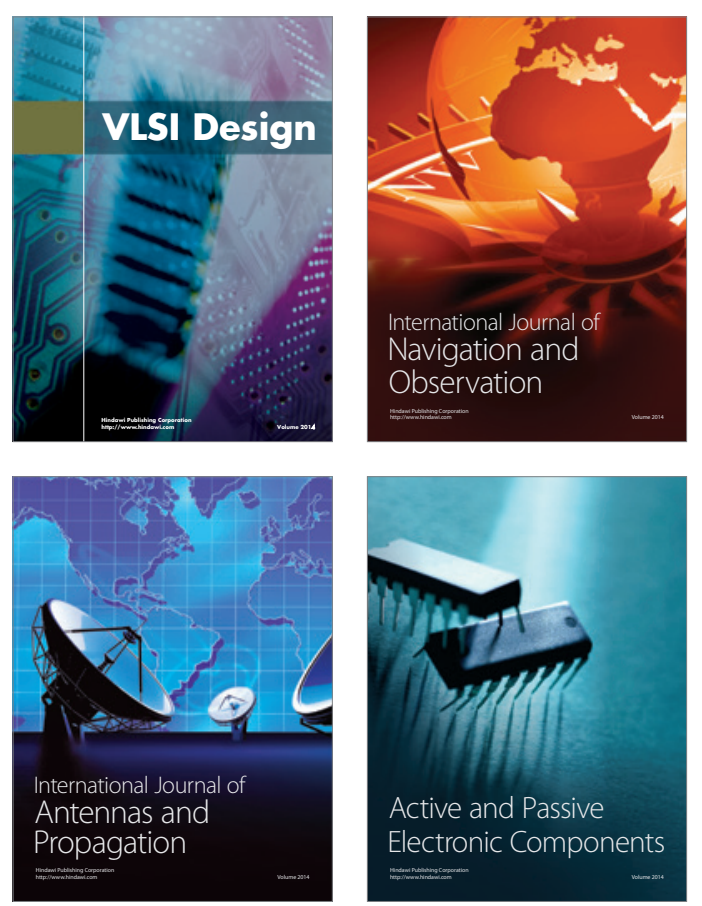
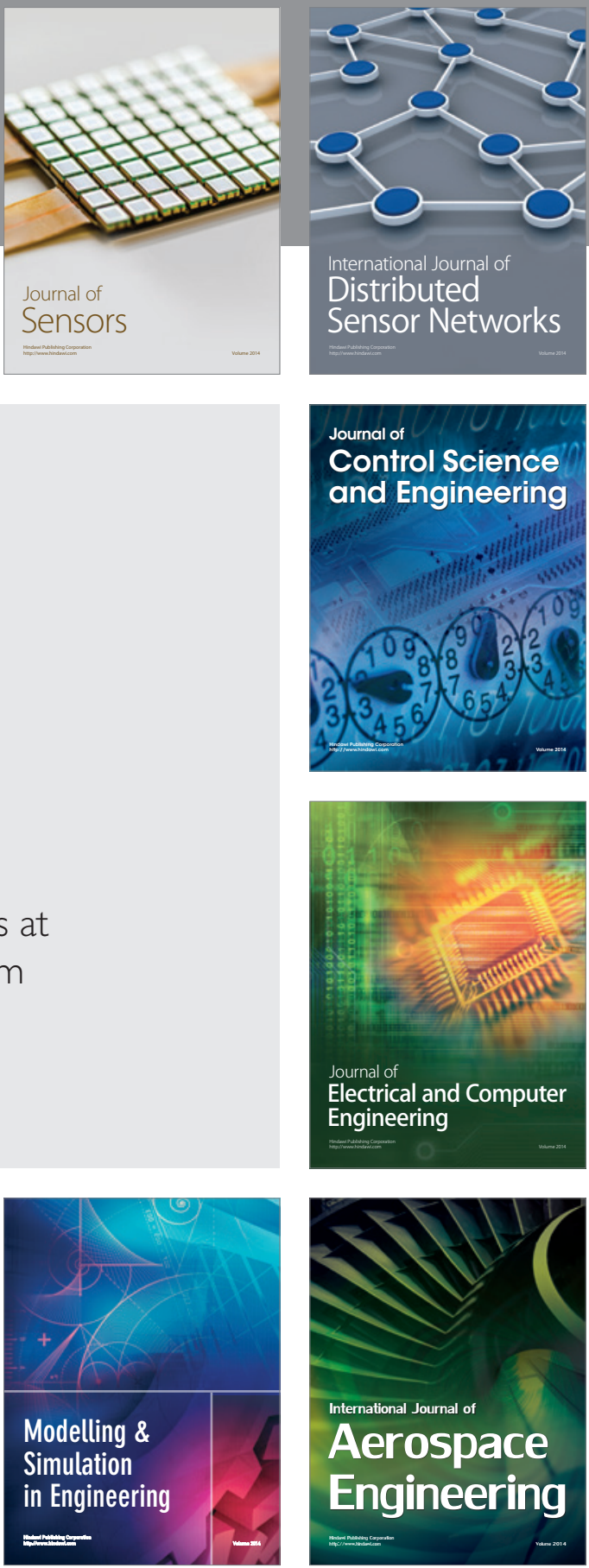

Journal of

Control Science

and Engineering
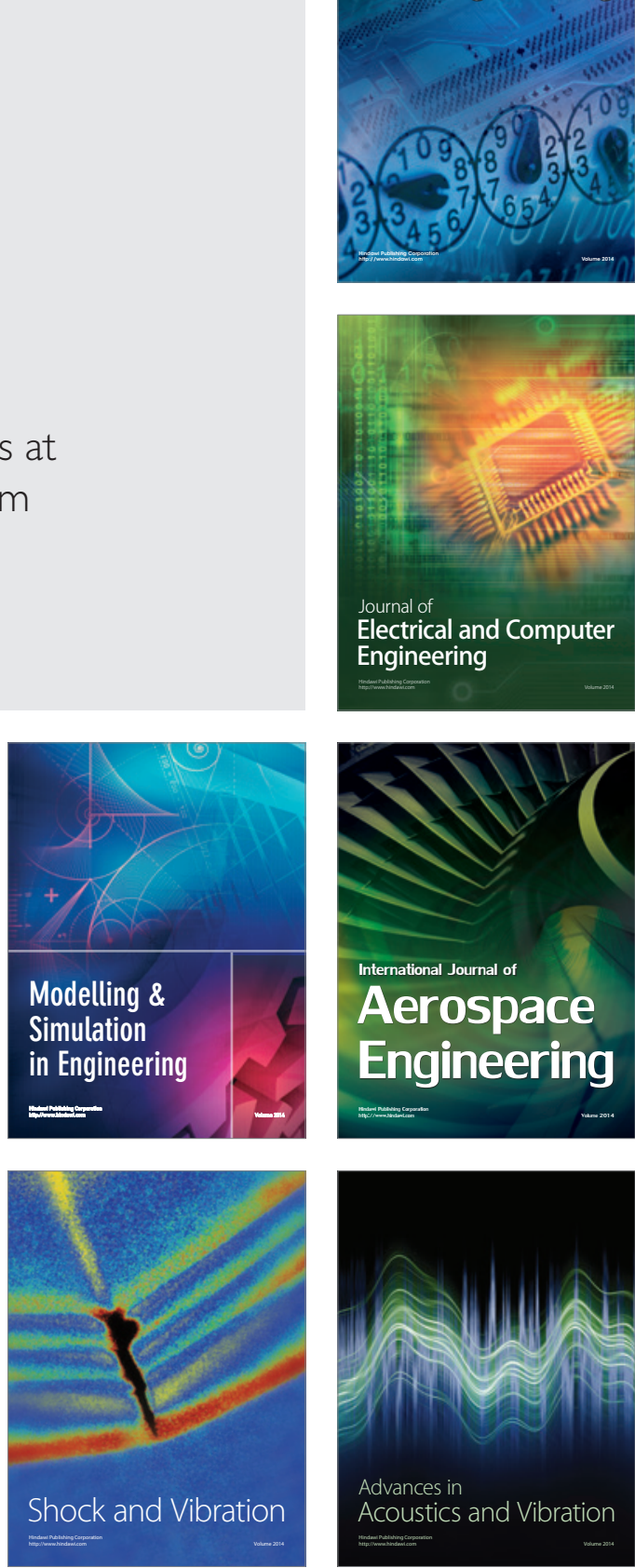